\title{
Bowel endometriosis mimicking gastrointestinal stromal tumor and diagnosed by endoscopic ultrasound
}

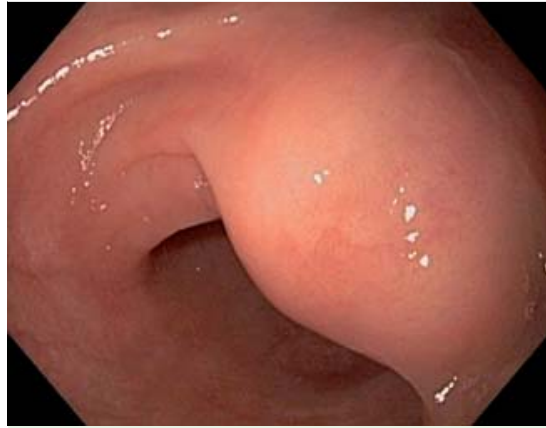

Fig. 1 Colonoscopic view of the rectosigmoid subepithelial lesion.

A 51-year-old asymptomatic woman was referred for colorectal cancer screening. During colonoscopy, a rectosigmoid subepithelial lesion was found, measuring approximately $2 \mathrm{~cm}$ and covered by normal mucosa ( Fig. 1). An endoscopic ultrasound (EUS) was performed to evaluate the lesion further. Radial and linear probes showed a hypoechoic lesion, measuring $22 \times 9 \mathrm{~mm}$, infiltrating the muscularis propria ( $\bullet$ Fig. 2, $\odot$ Fig. 3 and $\odot$ Fig.4). EUSguided fine-needle aspiration (EUS-FNA) of the lesion was performed using a 22gauge needle ( $\bullet$ Fig.5). Histopathological examination showed the presence of endometrial glands and stroma ( Fig.6).

Differentiating between subepithelial lesions may be difficult during regular colonoscopic evaluation. EUS is the best imaging procedure to evaluate subepithelial lesions in the gastrointestinal tract [1]. It is possible to assess the size, layer of origin, and the echotexture of the lesion, and to differentiate between an intramural and extramural lesion [2]. In most cases, a hypoechoic lesion, infiltrating the muscularis propria, favors the diagnosis of a gastrointestinal stromal tumor (GIST). However, the rectosigmoid region can be affected by a wide variety of conditions, including tumors such as lymphoma, leiomyoma, leiomyosarcoma, neuroendocrine tumor, and endometriosis.

Bowel endometriosis occurs in 3\%-37\% of women with endometriosis [3]. Up to $95 \%$ of intestinal endometriosis is found in the rectum and sigmoid colon [4]. Deep invasion of the intestinal wall is fre-

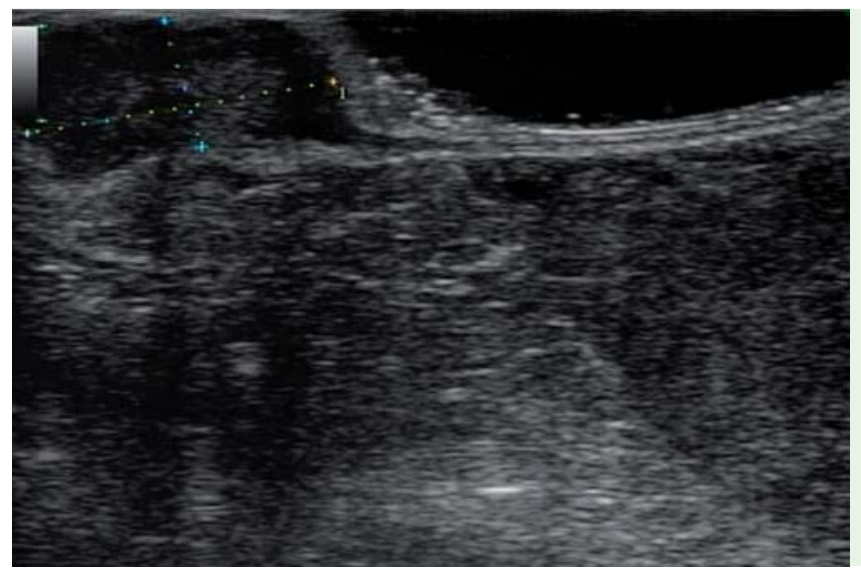

Fig. 2 Transrectal ultrasound (TRUS, linear probe): hypoechoic lesion measuring $22 \times 9 \mathrm{~mm}$.

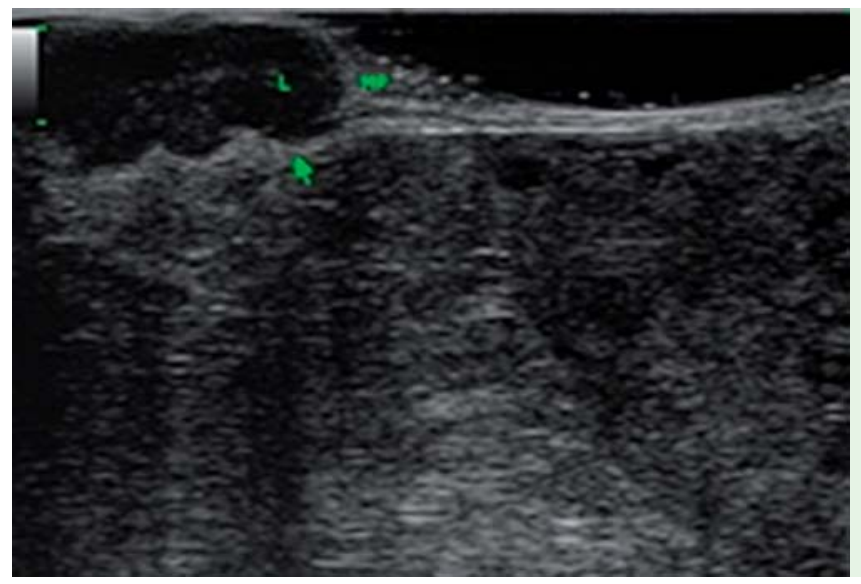

Fig. 3 Transrectal ultrasound (TRUS, linear probe): hypoechoic lesion infiltrating the muscularis propria of the rectosigmoid.

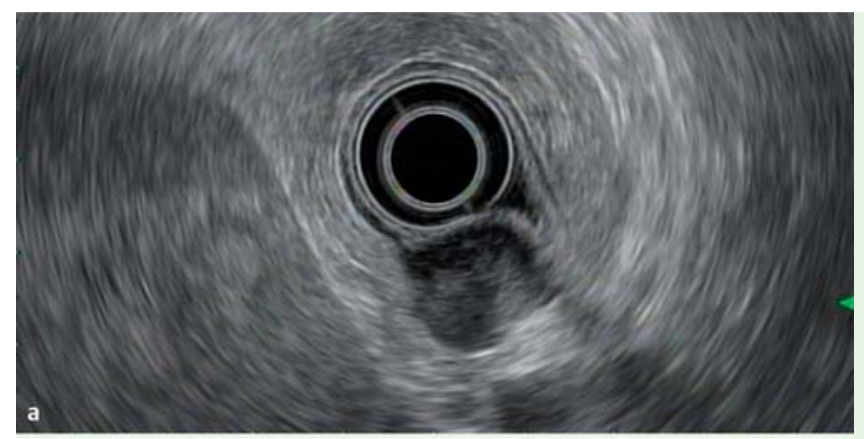

Fig.4 Endoscopic ultrasound images. a Radial probe: hypoechoic lesion infiltrating the muscularis propria of the rectosigmoid. b Linear probe: hypoechoic lesion infiltrating the muscularis propria of the rectosigmoid.

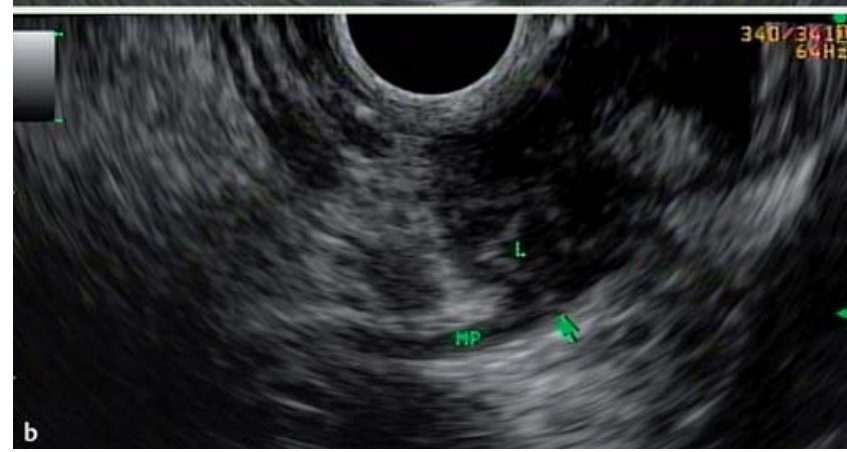




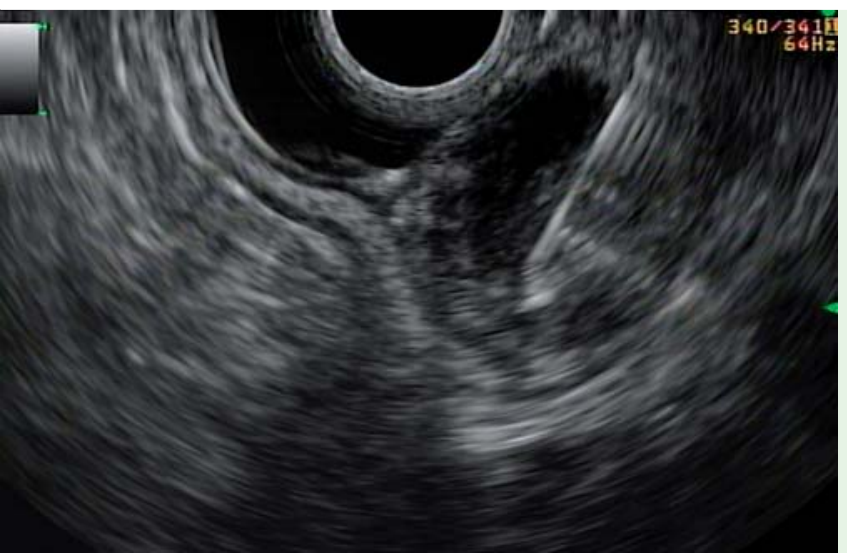

Fig. 5 Endoscopic ultrasound-guided fine-needle aspiration.

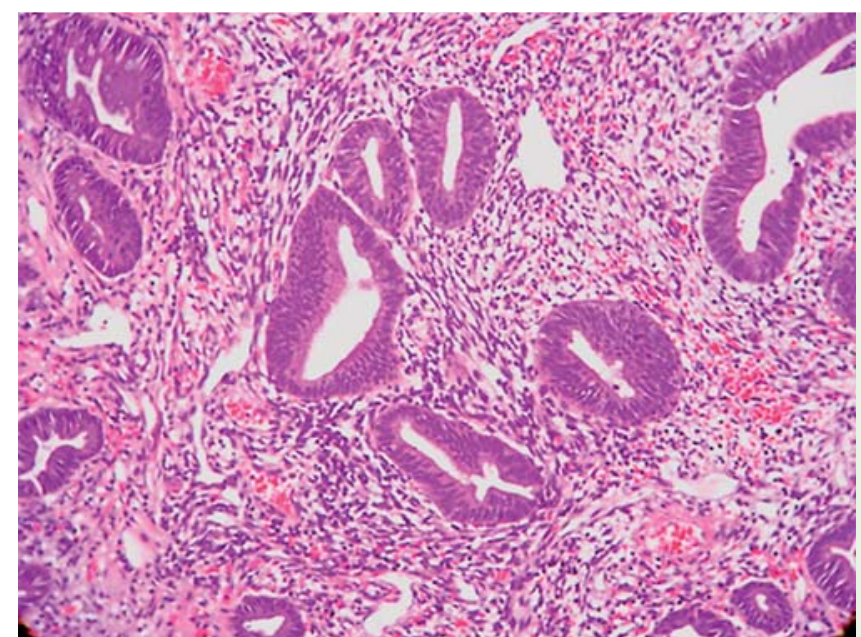

Fig. 6 Pathological specimen (hematoxylin and eosin stain) showing endometrial glands and stroma. quent, with infiltration of the muscularis propria or even of the submucosa. The mucosa is infiltrated in less than $5 \%$ of intestinal lesions. An accurate evaluation is indispensable for therapeutic decisions, and laparoscopic surgical resection of endometriotic lesions is the treatment of choice in symptomatic patients [5].
In the present case, it was possible to make a diagnosis of bowel endometriosis mimicking GIST using endoscopic ultrasound.

Endoscopy_UCTN_Code_CCL_1AF_2AH

Competing interests: None

\section{Rogerio Colaiacovo, Augusto Carbo- nari, Ricardo Ganc, Gustavo de Paulo, Angelo Ferrari}

Hospital Israelita Albert Einstein, Endoscopy unit, São Paulo, Brazil

\section{References}

1 Landi B, Palazzo L. The role of endosonography in submucosal tumours. Best Pract Res Clin Gastroenterol 2009; 23: 679-701

2 Polkowski M, Butruk E. Submucosal lesions. Gastrointest Endosc Clin N Am 2005; 15 : 33-54

3 Williams TJ, Pratt JH. Endometriosis in 1,000 consecutive celiotomies: incidence and management. Am J Obstet Gynecol 1977; 129: $245-250$

4 Chapron C, Fauconnier A, Vieira M et al. Anatomical distribution of deeply infiltrating endometriosis: surgical implications and proposition for a classification. Hum Reprod 2003; 18: 157-161

5 Rossini LG, Ribeiro PA, Rodrigues FC et al. Transrectal ultrasound - techniques and outcomes in the management of intestinal endometriosis. Endosc Ultrasound 2012; 1 : $23-35$

\section{Bibliography}

DOI http://dx.doi.org/

10.1055/s-0034-1377429

Endoscopy 2014; 46: E433-E434

(c) Georg Thieme Verlag KG

Stuttgart · New York

ISSN 0013-726X

\section{Corresponding author}

Augusto Carbonari, MD

Endoscopy Unit

Hospital Israelita Albert Einstein

Rua Manuel Figueiredo Landim 600

São Paulo

Brazil 04693-130

Fax: +55-11-997787804

augustocarbonari@gmail.com 